\title{
Educação a distância: o estado da arte e o futuro necessário
}

Gardênia da Silva Abbad

A Educação a distância (EAD), no mundo inteiro, é uma modalidade voltada à aprendizagem de adultos. Essa modalidade está vinculada a vários princípios educacionais, entre os quais os de aprendizagem aberta, aprendizagem ao longo de toda vida ou educação permanente. No Brasil, a EAD está sendo adotada na educação, nos programas de qualificação e formação profissional e na educação corporativa. Escolas de governo na Europa, no Canadá e no Brasil estão adotando a educação a distância, em todas as suas formas, na oferta de cursos para servidores públicos e comunidade.

Há escolas de governo européias que possuem programas bastante desenvolvidos de EAD, haja vista o Instituto de Gestão Pública e Desenvolvimento Econômico (IGPDE), da França, o Instituto Nacional de Administração Pública (Inap), da Espanha, e a Escola Canadense do Serviço Público (CSPS), do Canadá.

A ENAP Escola Nacional de Administração Pública, engajada nesse processo de ampliação do acesso à educação continuada e à aprendizagem ao longo da 
vida, oferece atualmente aos servidores públicos brasileiros mais de 20 cursos à distância através da sua Escola Virtual. O decreto 5.707, de 2006, sobre a Política Nacional de Desenvolvimento de Pessoal (PNDP), trouxe a capacitação do servidor público para o centro da questão e, como diretiva legal, passou a exigir da administração pública a adoção de estratégias mais eficazes de capacitação do servidor, para que serviços de qualidade possam ser oferecidos ao cidadão.

É crescente o número de instituições de ensino credenciadas pelo Ministério da Educação (MEC) para ofertar cursos à distância ou para empregar modalidades híbridas de ensino-aprendizagem como estratégia de democratização do acesso à educação. A educação corporativa no Brasil e em outros países está crescendo rapidamente, calcada na oferta de cursos por meio de ambientes virtuais de aprendizagem que possibilitam ao aluno e ao professor a interação assíncrona e a veiculação de objetos de aprendizagem pela Internet.

O profissional do presente e do futuro terá que pautar a sua aprendizagem no desenvolvimento de quatro grandes conjuntos de competências, necessários a uma aprendizagem ao longo de toda a vida. São eles, os pilares da educação, segundo Delors (2005):

- o aprender a conhecer: decorrente da necessidade de o indivíduo, em um cenário em que o conhecimento torna-se cada vez mais instável, estar continuamente inserido em um processo de compreensão, descoberta, construção e desconstrução do conhecimento. Mais do que aprender conteúdos é necessário conhecer linguagens e metodologias a partir das quais os conhecimentos são gerados e transferidos;

- o aprender a fazer: constitui-se no segundo pilar mencionado por Delors.
Relaciona-se a habilidades e atitudes supostamente capazes de tornar o indivíduo constantemente apto a enfrentar novas e desafiadoras situações, inclusive de trabalho. $\mathrm{Na}$ medida em que aumenta o descompasso entre as oportunidades de educação superior e as exigências impostas pelo mundo do trabalho, cada vez mais se torna insuficiente a preparação profissional para uma atividade específica e um realidade estática. É preciso que essa preparação seja contínua e abrangente;

- o aprender a viver junto: refere-se às habilidades e atitudes que permitem ao indivíduo conviver bem com outras pessoas em um cenário em que os trabalhos, cada vez mais complexos, exigem a atuação profissional em equipes interdisciplinares para a solução de problemas;

- o aprender a ser: refere-se ao desenvolvimento integral da pessoa. É preciso que o ser humano se desenvolva plenamente em todas as potencialidades.

Esses pilares oferecem os rumos para um processo educacional em que o "aprender a aprender" torna-se essencial, na medida em que o conhecimento baseado na compreensão da realidade assume posição de destaque no atual mundo do trabalho.

Muitas universidades abertas, em vários países do mundo, oportunizam aprendizagem ao adulto por meio de cursos à distância. Entre essas universidades estão: a University of South África (Unisa); a Fernuniversität, da Alemanha; a Open University, da Inglaterra; a Central Radio and Television University, da China; University of the Air, do Japão; a National University - Teleconference Network, dos EUA; a Contact North, do Canadá; a Universidade Aberta da Grécia, a Universidade Aberta da Coréia, a Universidad Nacional de Educación a Distancia (Uned); e a 
Universitat Oberta de Catalunya, da Espanha, entre outras.

A Open University, conforme Otto Peters (2001) foi a primeira universidade a distância a adotar o ensino aberto (open learning), em 1969, quando da sua fundação. Essa atitude levou outras 14 universidades a distância, sediadas em diversos países do mundo, a adotarem essa prática e o nome de universidades abertas. As demais 23 universidades a distância, de acordo com Peters (2001), também foram influenciadas por essas idéias desde a fundação da Open University.

A educação aberta baseia-se nos princípios da igualdade e do ensino permanente, acessível a qualquer pessoa, independentemente do seu perfil, a qualquer hora e em qualquer lugar. Oportuniza uma segunda chance a quem não pode concluir seus estudos ou uma primeira chance para outros que, de outro modo, não teriam acesso aos estudos. Entre esses estão mulheres, minorias étnicas, membros de comunidades geograficamente isoladas e distantes de instituições de ensino e pessoas de baixa renda, que deixam os estudos em busca de trabalho para sobrevivência.

Em organizações públicas e privadas, a EAD amplia e democratiza o acesso de pessoas ao estudo e cria condições propícias à aprendizagem contínua. $\mathrm{O}$ uso de plataformas eletrônicas de gerenciamento da aprendizagem tem possibilitado a armazenagem e a organização de verdadeiras universidades virtuais com serviços de orientação profissional, guias de estudo ou trilhas de aprendizagem, cursos mediados pela intra ou Internet, bibliotecas virtuais, textos e materiais de apoio ao estudo em diferentes áreas.

As comunidades virtuais de prática e de aprendizagem estão sendo adotadas na educação corporativa em empresas e em escolas de governo. A ENAP, por exemplo, estimula a formação desse tipo de comunidade através da inclusão dessa ferramenta como estratégia para unir pessoas em torno de temáticas de interesse recíproco e para apoiar a realização de cursos à distância mediados pela Internet.

A educação corporativa no Brasil, impulsionada pela EAD, tem aumentado as oportunidades de aprendizagem

"A educação aberta

baseia-senosprincípios

da igualdade e do ensino

permanente, acessível

a qualquerpessoa,

independentemente do

seu perfil, a qualquer

bora e em qualquer

lugar."

contínua de seus servidores, colaboradores, parceiros e demais constituintes de sua cadeia de valor.

Os dados do Anuário Brasileiro de Educação Aberta e a Distância (ABRAEAD), 2007, mostram o panorama da EAD em instituições de ensino e na educação corporativa no Brasil:

- aproximadamente 2.279 .070 brasileiros estudaram por EAD em 2006, por 
cursos oferecidos oficialmente credenciados e por grandes projetos nacionais públicos e privados;

- o número de instituições de ensino autorizadas a oferecer cursos à distância cresceu em 36,0\% no triênio em 2004-2006;

- o número de alunos que estudam nessas instituições cresceu cerca de 54\%, passando de 309.957 (em 2004), 504.204 (em 2005) para 778,458 (em 2006);

- o público-alvo dos cursos à distância oferecidos pelas 100 unidades de educação corporativa brasileiras é constituído por funcionários diretos $(59,30 \%)$, funcionários indiretos e prestadores de serviços $(33,30 \%)$ e outros $(25,90 \%)$;

- o nível hierárquico operacional é o mais visado pelas empresas, pois $85 \%$ delas ofertam seus cursos à distância para esse nível;

- o principal foco da EAD nas empresas é o treinamento (88,9\%), seguido pela reciclagem $(51,9 \%)$ e pelo aperfeiçoamento $(37 \%)$;

- as empresas ofertam uma grande variedade de cursos à distância, entre os tipos mais freqüentes estão: informática $(12,40 \%)$, educação e cidadania $(12,10 \%)$ e gestão $(10,10 \%)$;

- a duração média dos cursos à distância oferecidos pelas empresas gira em torno de 41 horas (mínimo de 8 horas e máximo de 255 horas).

- o grau de adesão dos funcionários aos cursos à distância é “excelente” (33,3\%) ou "bom" (48,10\%).

- o grau de satisfação dos funcionários com os cursos à distância é bastante favorável, pois na maior parte das empresas a avaliação atinge o conceito "bom" $(59,30 \%)$ ou "excelente" (37\%).

- o índice de evasão dos cursos é variável nas empresas. Os dados mostram que $59,30 \%$ das empresas registraram até
$20 \%$ de evasão, enquanto que $18,50 \%$ registraram evasão de $20 \%$ a $30 \%$, e $22,20 \%$ das empresas registraram um índice preocupante maior do que $30 \%$.

$O$ investimento na educação corporativa tem crescido bastante nos últimos anos, segundo informações contidas no ABRAEAD 2007 e tem se tornado um dos fatores de retenção de talentos nas empresas. Segundo pesquisa realizada pela Associação Brasileira de Treinamento e Desenvolvimento (20062007) para investigar a situação das ações de T\&D no Brasil, 70\% das empresas participantes da pesquisa registraram planejar investir mais recursos em treinamento em 2007, além de terem aumentado o número de horas destinadas a treinamento, que passou de 39 para 47 horas anuais. Essa média anual de horas de treinamento é superior aos índices internacionais registrados pelos EUA (30 horas), Europa (36 horas), Austrália (34 horas) e América Latina (31 horas).

Eboli (2004) descreveu 21 casos de universidades corporativas (UC) de empresas sediadas no Brasil ${ }^{1}$ e três casos de universidades setoriais ${ }^{2}$. Todas essas universidades, no momento da pesquisa, estavam implantadas ou em fase final de implantação. Além das universidades pesquisadas pela autora, há muitas outras, entre as quais as Universidades do Banco Central (Unibacen), da Petrobrás e da Eletronorte.

De acordo com informações contidas no ABRAEAD 2007, uma pesquisa realizada pelo CNPq sobre educação corporativa no contexto da política industrial, tecnológica e de comércio exterior mostrou que, no Brasil, há aproximadamente 100 unidades de educação corporativa. Esse número coloca o País em posição de destaque no cenário 
internacional, pois, segundo o ABRAEAD 2007, na Europa inteira, existem cerca de 100 unidades de educação corporativa, sendo que a Grã Bretanha e a Alemanha possuem 12 UCs, cada país; a França, cerca de 30; e a Rússia, 2 universidades.

Em função da relevância que a educação corporativa vem assumindo no Brasil, o Ministério do Desenvolvimento, Indústria e Comércio Exterior (MDIC), o Ministério da Educação (MEC) e o Ministério do Trabalho e Emprego (MTE) têm investido e apoiado programas de educação do trabalhador pelas organizações. Além disso, a formação profissional do trabalhador brasileiro tem sido impulsionada pela adoção da educação a distância e pelo investimento na ampliação do acesso a oportunidades de aprendizagem profissional continuada.

O SESI, o SENAI, o SENAC e o SEBRAE, órgãos do chamado Sistema $\mathrm{S}$, estão cada vez mais empenhados na criação de oportunidades de formação profissional a distância, mediadas por diversas tecnologias da informação e comunicação (televisão, rádio, material impresso, computador, DVD, ambientes virtuais de aprendizagem) e por formas puras e híbridas de situações de ensinoaprendizagem. As tecnologias educacionais desenvolvidas pelas unidades responsáveis pela educação profissional nos órgãos do Sistema S são avançadas, bem estruturadas e sistematicamente planejadas de acordo com os padrões de qualidade.

Há poucas pesquisas sobre o avanço da EAD no Serviço Público Brasileiro. A pesquisa publicada no ABRAEAD - 2007 abrangeu uma pequena amostra de instituições públicas brasileiras que adotam a EAD em suas unidades educacionais. Entre elas estão: a Escola de Governo de Mato Grosso; o Instituto Legislativo Brasileiro, do Senado Federal; a Marinha do Brasil; a Escola Fazendária da Secretaria da Fazenda do Estado de Pernambuco; o Serviço Federal de Processamento de Dados (Serpro); e o Instituto Serzedello Corrêa, do Tribunal de Contas da União.

No contexto do serviço público, a ENAP tem envidado esforços para conscientizar os profissionais de educação e gestão de pessoas sobre o importante papel da EAD na promoção de oportunidades de aprendizagem contínua aos servidores públicos e na ampliação do acesso ao estudo a qualquer hora e em qualquer lugar. Além de oferecer cursos à distância ao servidor público, a ENAP tem promovido relevantes debates sobre o papel da EAD no Brasil. Entre as iniciativas da ENAP, destaca-se a organização de um importante ciclo de debates em 2006, que resultou na produção do livro denominado Educação a distância em organizações públicas: mesa redonda de pesquisa-ação (2006), trabalho pioneiro e que servirá de marco inspirador para novas pesquisas e, quiçá, para mais investimentos em EAD.

O livro, redigido com base nos dados obtidos a partir da mesa redonda, possibilitou a descrição de tendências e perspectivas da EAD em algumas organizações públicas e privadas, entre as quais estavam: Banco do Brasil, Caixa Econômica Federal, Eletronorte, Empresa Brasileira de Correios e Telégrafos, Empresa Brasileira de Pesquisa Agropecuária, Escola Nacional de Administração Pública, Escola Nacional de Saúde Pública, Escola Superior de Administração Fazendária, Exército Brasileiro, Fundação Getúlio Vargas, Instituto Legislativo Brasileiro, Instituto Nacional de Seguro Social, Instituto Serzedello Corrêa, Ministério da Educação, Petrobrás, Serviço Brasileiro de Apoio a Micro e Pequenas empresas, Serviço 
Federal e Processamento de Dados, Serviço Nacional de Aprendizagem Comercial, Universidade do Banco Central do Brasil, Universidade Federal do Pará. Quase todas as unidades educacionais pesquisadas atendiam um público-alvo geograficamente disperso no território nacional, pertencente a uma ampla faixa etária (18 a 60 anos), com um predomínio de adultos mais idosos (de 30 a 60 anos de idade). Todas as unidades educacionais atendiam alunos com nível superior de instrução, sendo que algumas também atendiam alunos de nível médio e fundamental de escolaridade.

Os dados da pesquisa da ENAP indicam que o SENAC foi um dos pioneiros na adoção da EAD como modalidade de ensino-aprendizagem. Em 1947, o SENAC já veiculava cursos por meio de materiais impressos e rádio. A EAD, ao que parece, encontra-se em fase de expansão tanto no contexto da educação corporativa como no contexto da educação e treinamento no serviço público. A adoção da EAD como importante modalidade de ensino-aprendizagem não é nova no serviço público. Também merecem registro as experiências pioneiras do Exército Brasileiro e da Escola Superior de Administração Fazendária, que adotaram EAD em 1970 e 1975, respectivamente.

A EAD, ao que parece, encontra-se em fase de expansão na área de educação corporativa, de modo geral. As pesquisas da ABRAEAD - 2007, de Eboli (2004) e da ENAP mostraram que a educação corporativa brasileira teve seu crescimento acelerado na década de 1990. A adoção da EAD, entretanto, é ainda recente em muitas organizações brasileiras. O momento atual é o de consolidação das novas práticas educacionais à distância.

$\mathrm{Na}$ amostra pesquisada pela ENAP por ocasião da Mesa-redonda, nota-se que entre as organizações públicas pesquisadas, poucas possuem práticas institucionalizadas de EAD em suas organizações. Com exceção do Exército Brasileiro e da ESAF, as demais parecem estar em fase de consolidação e implantação de novas práticas educacionais. O Quadro 1 resume os relatos dos profissionais que participaram da Mesa-redonda na ENAP sobre a situação da EAD em suas respectivas organizações.

A EAD em órgãos públicos ainda é pouco difundida e institucionalizada, pelo menos no que tange a maior parte da amostra pesquisada pela ENAP por ocasião da Mesa-redonda de pesquisaação, anteriormente mencionada.

Em todas as organizações participantes da Mesa-redonda organizada pela ENAP, a EAD foi adotada como ferramenta de ampliação do acesso à educação, ao treinamento e à formação profissional e de apoio à introdução de mudanças tecnológicas nos processos de trabalho. Em todos esses casos, observase que a dispersão geográfica do públicoalvo foi importante motivo para a adoção da educação a distância baseada em diversas mídias (materiais impressos, rádio, televisão, vídeo, DVD, CD, ambientes virtuais de aprendizagem, computador).

Observa-se uma tendência clara de crescimento da oferta de cursos à distância em instituições de ensino e em empresas, o que resultou em um aumento do número de alunos beneficiados por essa modalidade educacional. Programas baseados em EAD para educação, formação, qualificação e treinamento estão crescendo no Brasil e no mundo. As oportunidades de educação ou treinamento em ambientes abertos de aprendizagem também têm sido oportunizadas por órgãos como Sebrae, universidades 
corporativas e instituições de ensino superior no Brasil.

Universidades abertas e a distância têm mudado a fisionomia da educação superior em diversos países, oferecendo oportunidades de estudo para pessoas que dificilmente seriam alcançadas pelo ensino convencional em sala de aula.

Os dados apresentados anteriormente mostram que a EAD é uma modalidade que facilita a inclusão e a democratização do acesso à educação e ao treinamento. A tendência de ampliação das clientelas de treinamento com o atendimento de diversos níveis hierárquicos pela educação corporativa são uma prova disso. Outra tendência parece ser a diversificação de temáticas abordadas nos cursos à distância. As organizações estão preocupadas em educar e não apenas treinar seus funcionários, pois os programas educacionais estão voltados para áreas de tecnologia, gestão, informática, educação, cidadania, entre outras relevantes.

Observa-se ainda que a EAD está sendo bem recebida pelos funcionários das empresas abrangidas pela pesquisa da ABRAEAD - 2007. Os níveis de adesão e satisfação com os cursos à distância são elevados e animadores. Entretanto, ainda permanecem altos os índices de evasão em boa parte das empresas estudadas. Em suma, a EAD é uma modalidade em expansão no Brasil e no mundo, tanto em contextos educacionais como na educação corporativa e profissional.

Mas, por que esse movimento está acontecendo e se ampliando na atualidade?

A rapidez das mudanças ocorridas no mundo do trabalho e as constantes inovações tecnológicas tornam necessária a aprendizagem rápida e eficaz, a constante aquisição, retenção e transferência de aprendizagem. Para aumentar a competência das pessoas e para que essas possam evitar a obsolescência profissional, tem havido intenso esforço de instituições de ensino e de qualificação profissional para criar oportunidades de aprendizagem contínua. Isso também é uma realidade no serviço público. Enquanto se enfrentam os desafios da inclusão digital, mesmo dentro do serviço público, busca-se oferecer um serviço de qualidade, eficiente, mais barato e mais rápido para o cidadão.

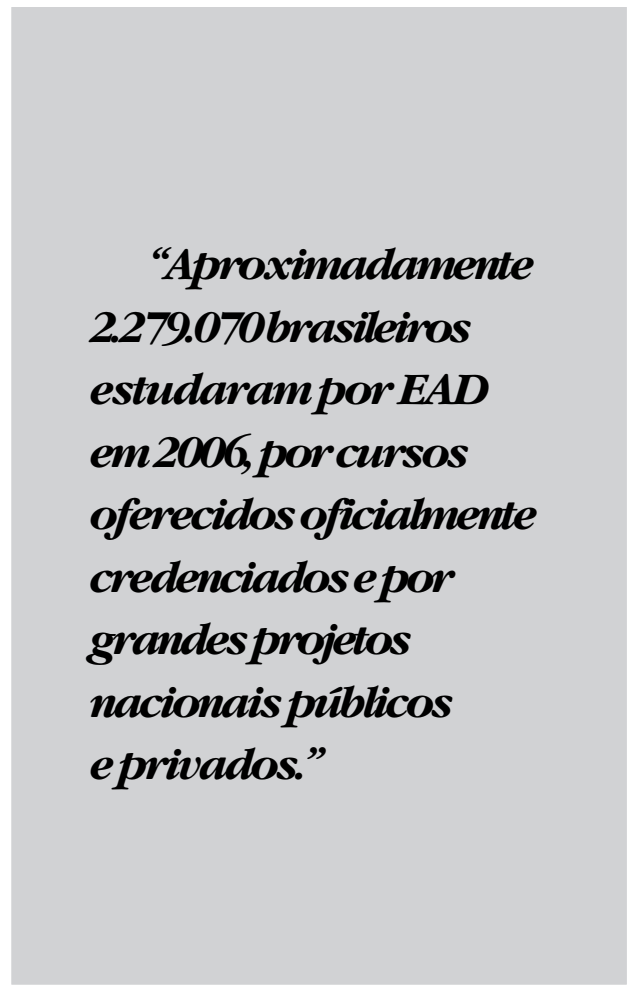

Os conhecimentos adquiridos pelas pessoas em quaisquer áreas de atuação e conhecimento estão sujeitos à rápida perda de validade. A abundância de informações, a intensa produção científica e tecnológica em todas as áreas do conhecimento humano e a possibilidade de ampla disseminação desses conhecimentos pelas redes globais de comunicação agem como pressões imperativas à aprendizagem 


\section{Quadro 1}

\begin{tabular}{|c|c|}
\hline Organização & Desafios e práticas de EAD \\
\hline ENAP & $\begin{array}{l}\text { A Escola oferece mais de } 20 \text { cursos à distância, com e sem tutoria. Como estratégias de } \\
\text { ensino-aprendizagem, a ENAP adota vários recursos de interação com estudo e exer- } \\
\text { cícios em salas de aula virtual, utilização de correio eletrônico e salas de bate-papo, } \\
\text { comunidades de aprendizagem e exercícios. O público-alvo dos cursos é formado por } \\
\text { servidores públicos. Desde a sua criação, em 2001, até 2006, a Escola Virtual da ENAP } \\
\text { havia oferecido cursos para milhares de servidores públicos brasileiros a custo zero } \\
\text { para suas instituições de origem. Em 2006, a ENAP atingiu a marca de } 20 \text { mil servi- } \\
\text { dores públicos concluintes de cursos à distância. A ENAP firmou acordos e parcerias } \\
\text { com escolas de governo de outros países (Espanha, França e Canadá) para promover } \\
\text { o intercâmbio de experiências em EAD. }\end{array}$ \\
\hline & $\begin{array}{l}\text { A modalidade de EAD parece estar institucionalizada na organização e vem sendo } \\
\text { empregada com sucesso como estratégia de ampliação do acesso ao treinamento e a } \\
\text { educação de estudantes lotados em todo o território nacional, desde a década de } 1970 \text {. A } \\
\text { EAD tem sido tratada como uma estratégia de inclusão de militares lotados em áreas } \\
\text { distantes dos grandes centros e que ficariam, sem a EAD, com dificuldades de acesso a } \\
\text { oportunidades educacionais e de treinamento. A grande capilaridade do Exército, presente } \\
\text { em todas as unidades da federação, tem facilitado a distribuição de materiais instrucionais } \\
\text { para militares do Brasil inteiro. A EAD, desde a sua implantação, tem oportunizado o } \\
\text { estudo a qualquer hora e em qualquer lugar, em função da adoção de atividades de } \\
\text { ensino-aprendizagem assíncronas e apoiadas em materiais didáticos de boa qualidade. } \\
\text { Em termos de desafios e tendências, foi relatado o interesse do Exército em ampliar e } \\
\text { aprofundar intercâmbios e parcerias com instituições de ensino na produção de ações } \\
\text { educacionais. Em } 2006 \text {, havia cerca de } 2.500 \text { militares realizando cursos de especialização } \\
\text { em instituições de ensino superior na modalidade a distância. }\end{array}$ \\
\hline $\begin{array}{l}\text { Senado } \\
\text { Federal } \\
\text { - ILB }\end{array}$ & $\begin{array}{l}\text { A EAD no ILD surgiu impulsionada pelas mudanças tecnológicas que se iniciaram } \\
\text { na rádio e na TV Senado e na informatização de todas as atividades da organização. } \\
\text { Havia demandas internas e externas de cursos que precisavam ser atendidas. Após um } \\
\text { levantamento de necessidades de treinamento, o instituto resolveu adotar a EAD } \\
\text { para ampliar o público-alvo para envolver profissionais de outros órgãos e países } \\
\text { (servidores, parlamentares do legislativo federal, estadual, distrital e municipal, dos } \\
\text { países de língua portuguesa, dos países do Mercosul, de instituições conveniadas com } \\
\text { o instituto e cidadãos), além de diversificar as temáticas e meios de ensino-aprendizagem } \\
\text { (Internet, vídeo e rádio). Ainda são incipientes as avaliações dos cursos e há muitos } \\
\text { desafios a enfrentar pela reduzida equipe que atua em educação nessa unidade educa- } \\
\text { cional. Um deles é aprimorar e desenvolver novas estratégias e técnicas educacionais e } \\
\text { de avaliação da efetividade das ações de EAD. }\end{array}$ \\
\hline Serpro & $\begin{array}{l}\text { A necessidade de adotar a EAD no Serpro surgiu em 1999, para a capacitação de } \\
\text { servidores de redes locais, alocados nas instalações da Secretaria da Receita Federal, em } \\
\text { todo o País, para trabalharem com uma nova versão de sistema operacional. Sem } \\
\text { condições financeiras para deslocar mais de } 1.000 \text { servidores no prazo requerido para } \\
\text { migração de um sistema operacional para outro, a equipe de suporte decidiu criar um } \\
\text { ambiente virtual para publicação de conteúdos didáticos com exemplos de telas de } \\
\text { utilização do novo sistema operacional com orientações de navegação. Para apoiar a } \\
\text { instrução foram criadas estratégias de interações entre alunos e tutores, através de } \\
\text { correio eletrônico e telefone. A experiência foi bem sucedida e, desde então, já foram } \\
\text { oferecidos mais de } 100 \text { cursos e capacitados mais de } 60.000 \text { alunos. }\end{array}$ \\
\hline
\end{tabular}


contínua. No Brasil, já é visível no serviço público e nas empresas a adoção de comunidades virtuais de prática e de aprendizagem para o compartilhamento de experiências, a troca de informações e a construção coletiva de novas soluções para problemas e desafios apresentados pelo trabalho. Essas comunidades virtuais têm sido mais um instrumento de aprendizagem para os profissionais, pois, ao permitir a reunião de pessoas interessadas em determinados assuntos, colabora para o processo de educação continuada.

A tendência mundial de aumento de complexidade dos trabalhos humanos em diferentes contextos e setores da economia, ocorrida em função da automação de atividades mais simples, além de acarretar a diminuição de postos de trabalho mais operacionais, causando desemprego daqueles indivíduos que não acompanharam as mudanças, tem exigido das pessoas um grande esforço de aquisição contínua de competências; e das instituições educacionais e organizações de trabalho, mais cuidado e uma preocupação em oferecer programas de educação continuada para adultos.

Grande parte das qualificações exigidas do trabalhador na atualidade é complexa e requer um conjunto de ações educacionais contínuas e variadas para desenvolvê-las. A idéia tem sido produzir currículos, trilhas de aprendizagem e estratégias de orientação de carreira profissional por meio das quais as pessoas possam buscar, de modo sistemático e racional, a aprendizagem e o desenvolvimento de amplos repertórios de qualificações durante toda a sua vida.

Entre os grandes desafios contemporâneos em EAD estão a inclusão digital e a familiarização das pessoas com as ferramentas da Internet, a melhoria dos cursos à distância, em especial das interações e da interatividade das estratégias de ensinoaprendizagem mediadas por novas tecnologias da comunicação e informação, bem como a adoção de sistemas de avaliação da efetividade das ações educacionais a distância. É preciso pesquisar as causas da evasão em cursos à distância de modo a reduzi-la. Outro desafio é demonstrar que a modalidade a distância é tão ou mais eficaz do que a modalidade tradicional com presença.

\section{Desafios para os profissionais de EAD}

As novas tecnologias de informação e comunicação impõem desafios para os profissionais que atuam na produção de cursos à distância. A articulação das mídias para a criação de ambientes propícios a aprendizagem é algo que requer muito esforço e competência técnica das equipes responsáveis pela educação na atualidade. Ao que tudo indica, há poucos profissionais preparados para enfrentar esses desafios. Ainda é comum a veiculação de livros eletrônicos em lugar de cursos interativos que requerem a participação ativa do aluno no processo de ensinoaprendizagem. No Brasil, é crescente a tentativa de incluir diferentes mídias e recursos tecnológicos na educação. Há muitos desafios no desenho de objetos e ambientes virtuais de aprendizagem. Entre os quais, destacam-se:

- a escolha da combinação adequada de encontros síncronos face-a-face ou mediados por tecnologias multiponto com interações assíncronas entre pessoas e com situações de auto-aprendizagem;

- a confecção de materiais de ensinoaprendizagem em diferentes meios, explorando com eficiência as potencialidades de 
cada um e as melhores combinações possíveis entre eles;

- o desenho dos ambientes virtuais de aprendizagem que integrem múltiplas mídias ou meios de ensino (materiais impressos, cd-roms, vídeos, fitas cassete, rádio, vídeo-conferências, simuladores, televisão, intranet ou Internet, entre outros),

- a escolha, a criação, a adaptação e a avaliação de diferentes modelos, desenhos e estratégias de ensino-aprendizagem em ambientes virtuais de aprendizagem e que possibilitem a simulação da realidade (ou o contato direto do aluno com ela), a experimentação, bem como a solução colaborativa de problemas relevantes;

- a necessidade muitas vezes conflitante de conferir, por um lado, flexibilidade ao desenho, favorecendo o estudo autônomo do aluno; e, por outro, a necessidade de desenhar e estruturar cuidadosamente as situações de aprendizagem, os feedbacks e a seqüência de apresentação de materiais, textos, exercícios e outros objetos de aprendizagem;

- a definição dos critérios válidos de avaliação da aprendizagem;

- a construção de medidas de avaliação de aprendizagem compatíveis com a natureza e o grau de complexidade dos objetivos educacionais, capazes de avaliar o efeito das situações de ensino sobre o rendimento do aluno;

- a avaliação da transferência de aprendizagem para o trabalho, bem como do suporte gerencial, psicossocial e material, ofertado ao egresso pelas organizações e ambientes de aplicação de novas aprendizagens, variáveis interferentes que dificultam a formulação de inferências sobre a relação entre o curso e seus efeitos no desempenho do egresso.

Porém, para se planejar sistematicamente as ações educacionais, respeitando a natureza dos processos psicológicos de aprendizagem, a retenção e a transferência, é preciso respeitar as diferenças individuais. Isso implica criar condições para que indivíduos com motivações, repertórios de entrada, estilos pessoais e níveis distintos de inteligência adquiram, igualmente, competências descritas nos objetivos educacionais.

Um dos grandes desafios da educação é, por um lado, garantir um alto grau de estruturação dos eventos instrucionais e, por outro, respeitar as diferenças individuais dos aprendizes.

Uma implicação dessa situação é que, para maximizar os ganhos para todos os perfis de aprendizes, não se poderia oferecer a mesma atividade educacional para todos. O ideal, em muitos casos, seria poder oferecer atividades personalizadas, de modo a otimizar os resultados de aprendizagem. Sistemas tutoriais inteligentes (multimídia) poderão, em um futuro próximo, viabilizar a custos razoáveis a personalização das experiências educacionais.

Outro desafio da educação de adultos é procurar desenvolver nas pessoas atitudes favoráveis de aceitação à diversidade humana. As mudanças demográficas, a entrada crescente de minorias no mercado de trabalho (por exemplo, idosos, mulheres, grupos étnicos, religiosos, e de orientação sexual minoritários, expatriados) e as ações afirmativas a elas associadas pressionam os indivíduos a aprender a lidar com diferenças em valores, crenças, manifestações das emoções, visões de mundo, costumes, hábitos de vida, vestuário, entre outras, e obriga a educação de adultos, além de propiciar o acesso ao estudo a essas minorias, a enfatizar a formação e o desenvolvimento dessas atitudes em seus programas e currículos.

Os fenômenos da globalização da economia e os que caracterizam a atualidade 
como a era do conhecimento viabilizaram e obrigaram as instituições educacionais a pensar em termos de educação global. $\mathrm{O}$ profissional do futuro deve, sob essa ótica, ser educado para compreender e agir nesse mundo globalizado e interligado por redes mundiais de comunicação e informação.

Uma sala virtual de aula pode, na atualidade, contar com alunos de diversas partes do globo terrestre. A interação entre pessoas de diferentes nacionalidades é uma realidade que não pode mais ser ignorada. As pessoas precisam aprender a trabalhar em equipes virtuais e saber articular-se à distância com outras pessoas para realizar tele-trabalhos e procurar espontaneamente as informações de que precisam para o trabalho.

O domínio de línguas estrangeiras passa a ser extremamente importante para a troca de experiências e a criação comunidades de aprendizagem com pessoas de diversas partes do mundo. A capacidade de comunicação e o uso adequado de novas tecnologias de informação e comunicação, nesse contexto, também são imprescindíveis para o sucesso profissional das pessoas.

A presença física de colegas e chefes não ocorrerá, em grande parte dos trabalhos, em um futuro bem próximo. Essa situação se reflete na educação contemporânea que precisa preparar as pessoas para essa realidade em que a autonomia e a iniciativa são requisitos necessários à sobrevivência no mercado de trabalho. A capacidade de pesquisar e selecionar informações relevantes também se configura em desafio para os profissionais e para a educação na atualidade.

Além dessas, será preciso desenvolver, articular e integrar competências ligadas ao "saber ser", como: habilidade de administrar o tempo e conciliar as atribuições e as responsabilidades concernentes aos diversos papéis sociais e esferas de vida (trabalho, família, relacionamento conjugal) que caracterizam o cotidiano do homem moderno.

O perfil do profissional do futuro caracteriza-se por um conjunto de habilidades estratégicas metacognitivas, bastante complexas, as quais capacitam a pessoa ao automonitoramento, à auto-avaliação e à autogestão da aprendizagem e carreira. O servidor público, como profissional inserido nesse contexto, precisa preparar-se

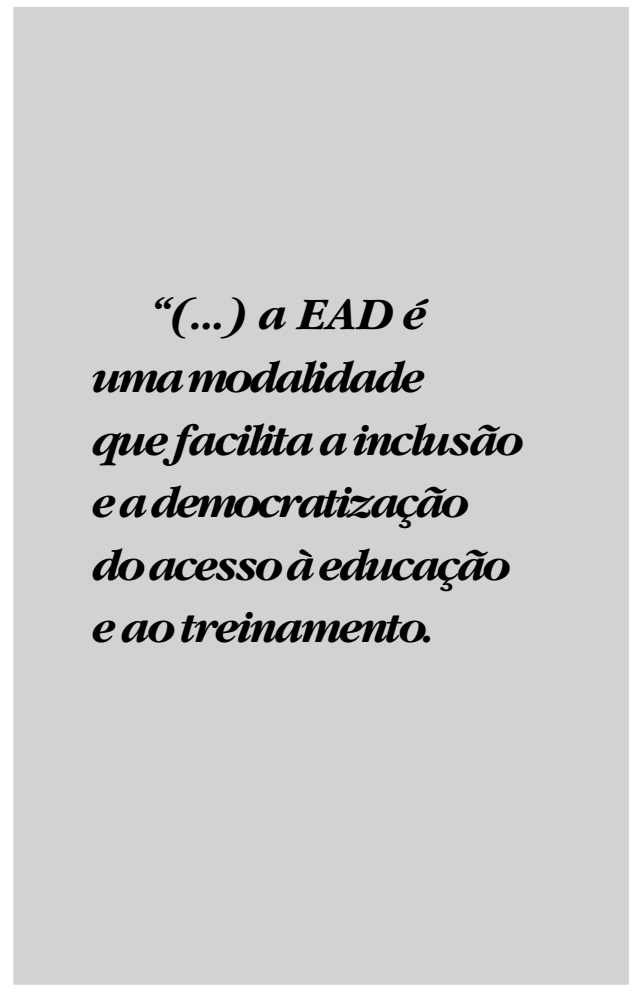

para incluir no seu cotidiano o auto-estudo, a administração do tempo para inserção de rotinas de aprendizagem contínua, o planejamento de carreira, a autogestão e a autonomia na busca ativa por novas aprendizagens. Essas complexas competências podem ser desenvolvidas por cursos à distância que estimulem a participação ativa do estudante nos processos de ensinoaprendizagem, tal como vem sendo feito 
em universidades abertas do mundo inteiro.

O novo profissional deve ser competente, isto é, saber agir com reflexividade e responsabilidade, segundo Zarifian (2001). Precisa ser criativo e encontrar novas soluções para problemas atuais, além de ser capaz de descobrir novos caminhos e oportunidades de crescimento e aprendizagem. Necessita, também, de desenvolver estratégias de auto-estudo e de busca e exploração de novos conhecimentos, habilidades e atitudes. Esses são os desafios para a educação.

Novas tecnologias de informação e comunicação, se bem empregadas em EAD, poderão ampliar o acesso de minorias sociais excluídas dos sistemas educacionais e de qualificação profissionais, bem como facilitar o desenvolvimento de muitas competências ora exigidas pela sociedade, em especial, pelo mundo do trabalho.

O uso cada vez mais freqüente de plataformas eletrônicas de gerenciamento da aprendizagem está viabilizando a entrega de cursos e de materiais didáticos a grandes massas de trabalhadores e estudantes adultos. Um mesmo curso pode ser atualmente disponibilizado para milhares de pessoas simultaneamente, que, nesses casos, precisam organizar-se para administrar os estudos e monitorar o próprio processo de aprendizagem.

Esses são cursos auto-instrucionais que requerem dos profissionais da área de educação um grande cuidado na elaboração de materiais didáticos, pois estes precisam estimular e induzir os processos de aprendizagem sem a presença de outras pessoas ligadas ao curso, como tutores, monitores e colegas.

Instituições de grande porte também estão investindo na criação de escolas para educação corporativa, e alguns setores da economia começam a criar universidades setoriais para garantir a educação permanente para a mão-de-obra e de toda a rede de stakeholders. Grande parte dessas empresas e instituições adota a EAD como a modalidade predominante. As escolas de governo também adotam a modalidade para oportunizar a aprendizagem contínua de seus públicos-alvo.

Em educação, como reflexo do contexto atual, fala-se muito em estudo autônomo e autonomia, definida como as capacidades de aprender a aprender; automonitorar-se; autocontrolar-se; e administrar próprio tempo de estudo.

Esse é o perfil de estudante almejado pelos educadores, empregadores e responsáveis pela oferta de cursos à distância. Porém, o adulto, que se beneficia desses cursos, é também um aluno de alto risco de desistência. Ele geralmente desempenha outros papéis na sociedade,que requerem atenção e disponibilidade de tempo.

A aprendizagem contínua e ao longo da vida, tão necessária a todos, depende de muitas condições externas ou fatores exógenos ao curso. Muitos deles não são controláveis pela instituição de ensino, porém podem e devem ser conhecidos previamente para que o planejamento e a oferta de cursos sejam compatíveis com a realidade e o cotidiano de seu público-alvo.

A falta de tempo para freqüentar classes tradicionais de ensino presencial é uma realidade para grande parte da clientela de EAD. A possibilidade de estudar em qualquer lugar e a qualquer hora é o que viabiliza a participação desse nosso adulto em ações de educação a distância. Esse é um desafio cuja solução seja, provavelmente, as formas híbridas (blended learning) de educação a distância, em que os encontros entre os atores - aluno-professor, aluno-aluno, alunomaterial, professor-professor, entre outros 
- possam criar vínculos que facilitem a aprendizagem, mantenham a motivação e aumentem as chances de permanência do aluno até o final do curso. Entretanto, pouco se sabe sobre qual seriam a freqüência e a intensidade ideais desses encontros presenciais, em diferentes tipos de curso (natureza, duração, número de alunos, perfil do público-alvo, recursos disponíveis).

Se por um lado a EAD é uma saída para os adultos que querem e necessitam estudar a vida inteira, por outro, ela impõe grandes desafios ao seu participante. Ele precisa desenvolver habilidades especiais para conciliar seus compromissos familiares, profissionais e acadêmicos com o estudo a distância. Ele precisa aprender a estudar mal acomodado em locais de trabalho, cheio de ruídos e interferências de outras pessoas, entre outras restrições. Esse público-alvo possui experiências e estilos de vida que devem ser respeitados no planejamento de situações de aprendizagem em EAD.

$\mathrm{Na}$ atualidade há uma nova compreensão sobre o papel da aprendizagem na sociedade. Aprender é um processo valorizado que exerce um papel central na vida humana. Aprender a estudar é imprescindível à aprendizagem contínua e permanente. Porém, isso é geralmente difícil de ser concretizado pelo adulto.

Nesse ponto parece relevante ressaltar alguns aspectos do perfil do aluno de EAD, suas expectativas e demandas que sugerem alguns desafios aos profissionais interessados na efetividade de cursos à distância.

O Quadro 1 mostra essa realidade.

O perfil do aluno de EAD impõe vários desafios aos responsáveis pela programação e oferta de cursos à distância, em função de suas demandas, expectativas e dificuldades para administrar o tempo para estudo.

Se essa realidade não for considerada antes e durante o desenho de cursos à distância os índices de abandono continuarão altos. Em alguns casos, há relatos de índices de em torno de 50\% de alunos evadidos em cursos à distância. Não foram localizadas pesquisas sobre evasão em cursos à distância no serviço público brasileiro.

No Brasil, segundo o ABRAEAD 2006, cerca de 23\% das instituições de ensino credenciadas pelo governo federal para oferecer EAD apresentam índices superiores a 30\% de evasão. Essa situação precisa ser revertida.

Apesar disso, há poucos estudos sistemáticos tratando da evasão em EAD, entre eles estão os de Shin e Kim (1999) e Xenos, Pierrakeas, e Pintelas (2002).

Para Xenos e seus colaboradores (2002), que realizaram uma pesquisa (dropout) na Universidade Aberta da Grécia, a evasão, uma das principais preocupações de instituições de ensino a distância, é causada por múltiplos fatores endógenos e exógenos ao curso. As pesquisas mostram, por exemplo, que, na maior parte dos casos, os estudantes que interromperam sua participação em um curso à distância o fizeram no início do curso, logo após o primeiro ou segundo módulo.

Há fatores que historicamente vêm afetando os níveis de evasão em cursos universitários à distância e que podem ser classificados em três grandes categorias, conforme Xenos (2002, et al).:

- fatores internos relacionados às percepções do aluno e ao seu locus de controle - interno-externo;

- fatores relativos ao curso e aos tutores; $\mathrm{e}$

- fatores relacionados a características demográficas dos estudantes, como: idade, sexo, estado civil, número de filhos, tipo de trabalho ou profissão, entre outras. 
Resultados interessantes, porém não conclusivos, mostraram que mulheres tendem a persistir mais do que os homens em cursos à distância. Em estudo recente, esse dado não foi confirmado em pesquisa nacional, na qual as pesquisadoras não encontraram diferenças entre estudantes homens e mulheres quanto aos níveis de abandono. (- AbBad; Carvalho; Zerbini, 2003). No Brasil, é preciso pesquisar essas questões ligadas a gênero e evasão em cursos à distância.

Quanto às características do desenho instrucional, os autores observaram que os níveis de evasão em cursos à distância são influenciados por fatores ligados ao desempenho do tutor, em termos de qualidade e quantidade de apoio que oferece ao estudante e por fatores ligados aos seus procedimentos do curso, como carga de trabalho, quantidade e dificuldade dos trabalhos escritos exigidos pelo curso.

Shin e Kim (1999) classificam as causas da evasão em cursos à distância em duas categorias distintas: fatores exógenos e endógenos. Ao avaliarem um curso de graduação na Universidade Nacional Aberta da Coréia consideraram três tipos de variáveis exógenas relacionadas à evasão:

- carga de trabalho: definida como a percepção do participante sobre o grau de exigência do trabalho que executa em seu emprego, externo à universidade;

- integração social: compreendida como as percepções que o participante possui sobre o apoio e encorajamento que recebe das pessoas que o rodeiam para estudar e sentir-se parte da universidade;

- desejo do aluno de concluir o curso. Entre as variáveis endógenas, estavam:

- tempo de estudo: a quantidade e o padrão de administração do tempo de estudo que o aluno adotou durante o semestre;
- planejamento da aprendizagem: referente ao grau de organização dos projetos individuais de aprendizagem, elaborados pelos estudantes; e

- atividades face-a-face: incluem a avaliação de quanto os alunos participaram de palestras complementares e o quanto necessitaram buscar apoio de outros colegas e escolas residenciais.

Abbad, Carvalho e Zerbini (2003) realizaram pesquisa para identificar variáveis explicativas da evasão em um curso gratuito à distância, via Internet, oferecido em nível nacional. Evasão, nesse estudo, referiase à desistência definitiva do aluno em qualquer etapa do curso. As variáveis antecedentes incluíram dados demográficos e de uso dos recursos eletrônicos. Os resultados indicaram que os participantes que acessaram poucas vezes os chats, o mural de notícias e o ambiente eletrônico do curso foram aqueles que também mais tenderam a abandonar o curso. Esses dados sugerem que os evadidos, no período de realização do curso, provavelmente ainda não dominavam o uso dos recursos baseados nas Novas Tecnologias de Informação e Comunicação (NTICs) ou não se sentiram estimulados a utilizá-los.

Esses dados, apesar de não conclusivos, mostram que os profissionais de EAD precisam identificar os fatores de risco de abandono típicos de cursos à distância. Alguns deles podem ser administrados mais facilmente pela instituição de ensino, enquanto outros requerem estratégias mais sofisticadas para superá-los.

O contexto de estudo do aluno também interfere decisivamente na efetividade de cursos à distância. O Quadro 2 resume os fatores comumente presentes no contexto do aluno de cursos a distância e que obstaculizam ou dificultam a sua aprendizagem e estudo. 
Quadro 2: A Clientela de EAD

\begin{tabular}{|c|c|c|c|}
\hline$O$ aluno de EAD & $\begin{array}{l}\text { Expectativas e } \\
\text { demandas }\end{array}$ & Desafios da EAD & $\begin{array}{l}\text { Potencialidades e } \\
\text { limitações da EAD }\end{array}$ \\
\hline $\begin{array}{l}\text { É adulto com } \\
\text { múltiplas } \\
\text { experiências } \\
\text { de vida. }\end{array}$ & $\begin{array}{l}\text { Espera que seus } \\
\text { conhecimentos e } \\
\text { experiências sejam } \\
\text { levados em conta } \\
\text { ao estudar. }\end{array}$ & $\begin{array}{l}\text { Escolher estratégias } \\
\text { participativas que } \\
\text { favoreçam o } \\
\text { aproveitamento dessas } \\
\text { experiências de vida no } \\
\text { processo de ensino- } \\
\text { aprendizagem. }\end{array}$ & $\begin{array}{l}\text { Uso de abordagens e } \\
\text { metodologias que facilitem a } \\
\text { criação de situações de } \\
\text { aplicação prática e resolução } \\
\text { de problemas. }\end{array}$ \\
\hline $\begin{array}{l}\text { Acumula } \\
\text { diversos } \\
\text { papéis na } \\
\text { sociedade. }\end{array}$ & $\begin{array}{l}\text { Espera que as } \\
\text { dificuldades de } \\
\text { conciliar } \\
\text { responsabilidades } \\
\text { pessoais, profissionais e } \\
\text { de estudo sejam } \\
\text { percebidas e } \\
\text { consideradas pelos } \\
\text { profissionais } \\
\text { responsáveis pela } \\
\text { concepção e entrega } \\
\text { de soluções educacionais }\end{array}$ & $\begin{array}{l}\text { Oportunidades de } \\
\text { estudar a qualquer hora } \\
\text { e em qualquer lugar. } \\
\text { Horários e tempos de } \\
\text { estudo flexíveis, } \\
\text { compatíveis com as } \\
\text { rotinas profissionais e } \\
\text { pessoais. } \\
\text { Interações assíncronas. }\end{array}$ & $\begin{array}{l}\text { Preparação de materiais auto- } \\
\text { instrucionais com escolha de } \\
\text { mídias compatíveis como } \\
\text { contexto e perfil do } \\
\text { estudante. } \\
\text { Uso de recursos baseados nas } \\
\text { novas tecnologias da } \\
\text { informação para } \\
\text { armazenagem, acesso on-line } \\
\text { a objetos de aprendizagem e } \\
\text { comunicação assíncrona } \\
\text { entre os atores do processo de } \\
\text { ensino-aprendizagem. }\end{array}$ \\
\hline $\begin{array}{l}\text { Possui } \\
\text { experiências } \\
\text { profissionais e } \\
\text { busca melhoria } \\
\text { de status } \\
\text { socioeconômico. }\end{array}$ & $\begin{array}{l}\text { Espera situações de } \\
\text { aprendizagem } \\
\text { compatíveis com o seu } \\
\text { perfil profissional e que } \\
\text { tenham impacto } \\
\text { favorável sobre a vida } \\
\text { profissional. }\end{array}$ & $\begin{array}{l}\text { Necessita de situações de } \\
\text { aprendizagem que } \\
\text { elevem as suas } \\
\text { competências em termos } \\
\text { de complexidade e } \\
\text { relevância prática. }\end{array}$ & $\begin{array}{l}\text { Desenho baseado na avaliação } \\
\text { do perfil profissional do } \\
\text { público-alvo. } \\
\text { Flexibilidade na seqüencia de } \\
\text { apresentação de conteúdos. } \\
\text { Pré-teste para ingresso no } \\
\text { curso e em cada parte do } \\
\text { mesmo. } \\
\text { Possibilidade de orientação } \\
\text { e feedback individualizados. } \\
\text { Condições propícias pra a } \\
\text { criação de exercícios que } \\
\text { requeiram respostas abertas e } \\
\text { solução de problemas relacio- } \\
\text { nados às atividades profissio- } \\
\text { nais do aluno. } \\
\text { Esse tipo de estratégia é de } \\
\text { difícil implementação para } \\
\text { grandes amostras de } \\
\text { estudantes. }\end{array}$ \\
\hline
\end{tabular}


Quadro 2: A Clientela de EAD (continuação)

\begin{tabular}{|c|c|c|c|}
\hline $\mathrm{O}$ aluno de EAD & $\begin{array}{l}\text { Expectativas e } \\
\text { demandas }\end{array}$ & Desafios da EAD & $\begin{array}{l}\text { Potencialidades e } \\
\text { limitações da EAD }\end{array}$ \\
\hline $\begin{array}{l}\text { É } \\
\text { profissionalmente } \\
\text { ativo. }\end{array}$ & $\begin{array}{l}\text { Espera que as mídias de } \\
\text { entrega dos conteúdos e } \\
\text { os recursos de apoio } \\
\text { sejam compatíveis e } \\
\text { adequados às rotinas de } \\
\text { trabalho. }\end{array}$ & $\begin{array}{l}\text { Utilização de múltiplas } \\
\text { mídias e serviços de } \\
\text { tutoria e monitoria } \\
\text { compatíveis com } \\
\text { horários de estudo. }\end{array}$ & $\begin{array}{l}\text { Há mídias mais ou menos } \\
\text { flexíveis e nem todas são } \\
\text { adequadas ao tipo de } \\
\text { objetivo educacional do } \\
\text { curso. }\end{array}$ \\
\hline $\begin{array}{l}\text { É mais } \\
\text { qualificado que } \\
\text { estudantes de } \\
\text { cursos } \\
\text { presenciais. }\end{array}$ & $\begin{array}{l}\text { Espera não ter que } \\
\text { memorizar informações } \\
\text { pouco complexas e } \\
\text { disponíveis no contexto } \\
\text { de estudo e de trabalho. } \\
\text { Necessita solucionar } \\
\text { problemas reais e } \\
\text { relevantes. }\end{array}$ & $\begin{array}{l}\text { Criar ambientes } \\
\text { interativos de } \\
\text { aprendizagem. } \\
\text { Criar situações em } \\
\text { que a participação ativa } \\
\text { o aluno é decisiva para } \\
\text { a solução de problemas } \\
\text { ligados ao contexto de } \\
\text { estudo. }\end{array}$ & $\begin{array}{l}\text { É possível criar estratégias em } \\
\text { que a interação entre pessoas } \\
\text { (aluno-tutor, aluno-aluno) } \\
\text { seja estimulada. } \\
\text { Uso de simuladores e de } \\
\text { metodologias baseadas em } \\
\text { resolução colaborativa de } \\
\text { problemas, webquests, entre } \\
\text { outros, são possíveis. Porém, } \\
\text { os custos iniciais para o } \\
\text { desenvolvimento desse tipo } \\
\text { de tecnologia são altos. }\end{array}$ \\
\hline $\begin{array}{l}\text { Valoriza o estudo } \\
\text { em função de } \\
\text { ciclos e planos } \\
\text { de vida. } \\
\text { É motivado para } \\
\text { a aprendizagem. }\end{array}$ & $\begin{array}{l}\text { Espera ter experiências } \\
\text { de estudo que facilitem } \\
\text { o alcance de objetivos } \\
\text { profissionais e pessoais. }\end{array}$ & $\begin{array}{l}\text { Compatibilizar as } \\
\text { características do curso } \\
\text { ao perfil motivacional } \\
\text { do aluno (produtos e } \\
\text { competências resultantes } \\
\text { do curso valorizadas } \\
\text { pela clientela). }\end{array}$ & $\begin{array}{l}\text { Possibilidade de uso de } \\
\text { inteligência artificial para } \\
\text { adequação do desenho do } \\
\text { curso ao aluno. } \\
\text { Limitação: essas tecnologias } \\
\text { ainda são pouco acessíveis. }\end{array}$ \\
\hline $\begin{array}{l}\text { Luta contra a } \\
\text { obsolescência } \\
\text { profissional. }\end{array}$ & $\begin{array}{l}\text { Necessita atualizar-se e } \\
\text { re-qualificar-se de modo } \\
\text { contínuo, ao longo de } \\
\text { toda a vida. }\end{array}$ & $\begin{array}{l}\text { Armazenar, indexar e } \\
\text { disponibilizar } \\
\text { informações relevantes, } \\
\text { mecanismos de } \\
\text { orientação profissional e } \\
\text { trilhas de aprendizagem. }\end{array}$ & $\begin{array}{l}\text { Uso de plataformas } \\
\text { eletrônicas de gerenciamento } \\
\text { da aprendizagem. } \\
\text { Acesso a bibliotecas virtuais. } \\
\text { Acesso e estímulo a formação } \\
\text { de comunidades virtuais de } \\
\text { aprendizagem. }\end{array}$ \\
\hline
\end{tabular}

O planejamento de cursos à distância, dado os índices de evasão de alunos que caracterizam o campo, deveria, idealmente, pautar-se em pesquisa prévia sobre o perfil do público-alvo, em termos de características demográficas e profissionais; conhecimento prévio dos temas abordados no curso; habilidade para a utilização da Internet; características cognitivas e atitudinais, como hábitos de estudo, estratégias e estilos de aprendizagem, locus de controle e autoeficácia; e características motivacionais, como motivação para aprender, valor instrumental do curso para o indivíduo. 
Essas variáveis têm sido pesquisadas em avaliação de ações organizacionais de Treinamento, Desenvolvimento e Educação (TD\&E). Resultados de pesquisas sobre cursos presenciais revelaram correlações entre características pessoais do participante e aprendizagem, reações e a aplicação eficaz das novas aprendizagens no ambiente de trabalho.

A EAD possui algumas potencialidades ainda pouco exploradas. Há cursos cujo desenho é inadequado à realidade do público-alvo. O Quadro 3 mostra algumas dessas potencialidades e falhas.

O uso de novas tecnologias de informação e comunicação abre um universo de possibilidades ainda pouco exploradas em EAD. O material impresso ainda é o meio de transmissão de conteúdos mais utilizado no Brasil e, provavelmente, no mundo inteiro. A ele agregam-se outras mídias para apoiar o ensino com presença ou para constituir-se em material auto-instrucional.

Plataformas eletrônicas de fornecimento universal e instantâneo de informações possibilitam um gerenciamento mais efetivo do conhecimento humano e possibilitam atualização, armazenamento, recuperação, distribuição e compartilhamento instantâneos de grandes quantidades e variedades de informações. Essas informações são transmitidas em rede on-line.

A comunicação entre as pessoas também pode ocorrer em tempo real no ciberespaço. Existe a possibilidade de conectar pessoas de quaisquer partes do mundo. A comunicação através da Internet rompe barreiras físicas e temporais entre as pessoas e viabiliza trocas e intercâmbios síncronos e assíncronos, nunca antes imaginados.

Essas tecnologias possibilitam a produção de objetos eletrônicos de aprendizagem, que podem ser recombinados para formar aulas, manuais, folhetos, cursos inteiros, textos, hipertextos, hipermídias e hiperbases de dados. Novas soluções educacionais podem ser desenhadas, em diversos formatos, com suporte e tutoria eletrônica e com desenhos mais ou menos personalizados. Porém, a aplicação dessas tecnologias ainda não é muito comum em EAD. O Quadro 4 mostra algumas potencialidades da aplicação de NTICs em EAD.

Muitos fatores mostram que há especificidades ligadas à EAD e ao perfil do aluno que merecem atenção dos educadores. Essas características do participante devem ser consideradas pelo responsável pelo planejamento de cursos à distância, ao escolherem teorias de aprendizagem, abordagens instrucionais e de desenho instrucional compatíveis com as demandas e contexto do estudante.

Essas características e potencialidades da EAD precisam ser exploradas pela educação corporativa, por escolas de governo e pelas demais unidades educacionais, de modo a ampliar o acesso à educação e aumentar a sua efetividade. A adoção de formas educacionais mistas, apoiadas em diferentes mídias, tem o potencial de democratização, ao atender profissionais, cujo contexto de trabalho e de vida são pouco propícios ao estudo ao longo da vida.

Em suma, o Estado da Arte

Houve, nas últimas quatro décadas, um aumento da oferta de cursos à distância, provavelmente no mundo inteiro, com universidades, escolas de governo, universidades corporativas e outras instituições ligadas a qualificação profissional adotando a modalidade de EAD para oferecer oportunidades de aprendizagem a um número cada vez maior de pessoas. 


\section{Quadro 3: O contexto da clientela de EAD}

\begin{tabular}{|c|c|c|c|}
\hline $\mathrm{O}$ aluno de EAD & $\begin{array}{l}\text { Expectativas e } \\
\text { Demandas }\end{array}$ & Desafios da EAD & $\begin{array}{l}\text { Potencialidades e } \\
\text { Limitações da EAD }\end{array}$ \\
\hline $\begin{array}{l}\text { Enfrenta } \\
\text { problemas e } \\
\text { situações da vida } \\
\text { adulta que } \\
\text { concorrem com } \\
\text { os estudos e } \\
\text { podem causar } \\
\text { evasão (familiares, } \\
\text { conjugais, } \\
\text { profissionais). }\end{array}$ & \begin{tabular}{|l} 
Espera espaço para \\
negociação de prazos \\
para cumprimento das \\
atividades previstas na \\
programação do curso. \\
Necessita de auxílio \\
acadêmico e pessoal \\
para enfrentar as \\
dificuldades.
\end{tabular} & $\begin{array}{l}\text { Propiciar serviços de } \\
\text { tutoria ativa, que se } \\
\text { preocupa em descobrir } \\
\text { meios de auxiliar o } \\
\text { aluno a superar as } \\
\text { dificuldades pessoais } \\
\text { em abandonar o curso. }\end{array}$ & \begin{tabular}{|l} 
O uso de NTICs pode \\
facilitar o contato do tutor \\
com o aluno. \\
Possibilidade de diferenciar \\
os perfis de alunos que \\
abandonam e que concluem \\
cursos à distância e criar \\
guias de estudo e procedi- \\
mentos de administração \\
do tempo de estudo com \\
base nesses dados.
\end{tabular} \\
\hline $\begin{array}{l}\text { Os horários de } \\
\text { estudo não são } \\
\text { fixos e, muitas } \\
\text { vezes, ficam } \\
\text { restritos ao } \\
\text { período noturno, } \\
\text { após longa } \\
\text { jornada de } \\
\text { trabalho. } \\
\text { Dispõe de pouco } \\
\text { tempo diário para } \\
\text { estudo. }\end{array}$ & $\begin{array}{l}\text { Espera que a progra- } \\
\text { mação e cronograma } \\
\text { do curso respeitem essa } \\
\text { realidade e estimem } \\
\text { de modo realista as } \\
\text { cargas horárias neces- } \\
\text { sárias para conclusão } \\
\text { de cada atividade do } \\
\text { curso. }\end{array}$ & $\begin{array}{l}\text { Criação de mecanismos } \\
\text { de gestão do tempo de } \\
\text { estudo e espaço para } \\
\text { negociação de prazos } \\
\text { para realização de } \\
\text { atividades. }\end{array}$ & $\begin{array}{l}\text { Possibilidade de prevenir o } \\
\text { abandono a partir da } \\
\text { identificação pelo tutor de } \\
\text { sinais de dificuldades e } \\
\text { intervenção imediata para } \\
\text { resgatar o aluno. }\end{array}$ \\
\hline $\begin{array}{l}\text { Quando consegue } \\
\text { dispõe de pouco } \\
\text { tempo de } \\
\text { cada vez. } \\
\text { É interrompido } \\
\text { com freqüência } \\
\text { em seus horários } \\
\text { de estudo. } \\
\text { Os locais de } \\
\text { estudo também } \\
\text { variam e muitas } \\
\text { vezes são } \\
\text { inadequados ao } \\
\text { estudo e à reflexão. }\end{array}$ & & $\begin{array}{l}\text { Preparar cursos compa- } \\
\text { tíveis com o cotidiano, } \\
\text { contexto de estudo e } \\
\text { estilo de vida do aluno. } \\
\text { Propiciar locais para } \\
\text { estudo individual. }\end{array}$ & $\begin{array}{l}\text { Fixar local para estudo pode } \\
\text { estimular um comporta- } \\
\text { mento incompatível com } \\
\text { um dos princípios da EAD } \\
\text { referente ao estudo em } \\
\text { a qualquer hora e em } \\
\text { qualquer local. }\end{array}$ \\
\hline
\end{tabular}


Entretanto, há índices altos de evasão e abandono em cursos à distância e poucos estudos sistemáticos sobre as suas causas.

Além disso, a produção de pesquisas ainda não tem sido suficiente para produzir conhecimentos sobre a efetividade de cursos à distância; as tecnologias existentes ainda não têm sido utilizadas em todas as suas potencialidades como recursos de apoio à aprendizagem; as ferramentas de interação ainda limitam muito o contato e a solução colaborativa de problemas entre pessoas; ou seja, praticamente não há estudos sistemáticos sobre efeitos das diferenças individuais sobre os níveis de aprendizagem e transferência de aprendizagem em cursos à distância.

Ainda são raros os estudos de análise de necessidades educacionais que identifiquem previamente as características dos contextos de estudo, aprendizagem e transferência de aprendizagem do público-alvo de EAD, tão necessários ao desenho e avaliação da efetividade de cursos à distância.

Há outros problemas, cuja solução também é urgente e necessária, porém que não têm têm sido pesquisados a contento, como as seguintes questões:

- Por que, em algumas situações, ainda são altos os índices de evasão em cursos à distância?

- Em que devem diferir os materiais instrucionais em cada mídia?

- Blended learning produz menor evasão e maior aprendizagem do que a forma pura totalmente à distância?

- Como o lidar com a diversidade humana em cursos à distância, de modo que todos os perfis sejam beneficiados igualmente pelo curso?

Quanto ao futuro necessário, sugere-se:

- - construção e validação de modelos de avaliação da efetividade de cursos à distância (auto-instrucionais, blended-learning),

\section{Quadro 4: Potencialidades e falhas da EAD}

\begin{tabular}{|l|l|}
\hline Potencialidades da EAD & Falhas \\
\hline $\begin{array}{l}\text { Ampliação do acesso à educação . } \\
\text { formal }\end{array}$ & $\begin{array}{l}\text { Materiais pouco acessíveis aos estudantes de } \\
\text { baixa renda. }\end{array}$ \\
\hline $\begin{array}{l}\text { Ampliação do acesso à formação e } \\
\text { qualificação profissionais. }\end{array}$ & $\begin{array}{l}\text { Uso de mídias e materiais incompatíveis com o } \\
\text { contexto e habilidades do aluno. }\end{array}$ \\
\hline $\begin{array}{l}\text { Desenvolvimento de competências } \\
\text { complexas valiosas como: autonomia, } \\
\text { auto-estudo, auto-avaliação, } \\
\text { administração do tempo, autogestão } \\
\text { de carreira. }\end{array}$ & $\begin{array}{l}\text { Apoio inadequado ao estudo (muitos alunos por } \\
\text { tutor ou, falta de interação com outros, falta de guias, } \\
\text { orientações e mapas de estudo e de tutoria ativa). }\end{array}$ \\
\hline $\begin{array}{l}\text { Utilização de múltiplas mídias de } \\
\text { entrega de materiais. }\end{array}$ & $\begin{array}{l}\text { Falta de preparação prévia do aluno para manusear os } \\
\text { recursos da informática para estudar. }\end{array}$ \\
\hline $\begin{array}{l}\text { Oportunidade de estudo a qualquer } \\
\text { hora e em qualquer lugar. }\end{array}$ & $\begin{array}{l}\text { Dificuldade de estudar em local apropriado. } \\
\text { Horários variáveis e pouco tempo de estudo de } \\
\text { cada vez. }\end{array}$ \\
\hline $\begin{array}{l}\text { Flexibilidade para escolher a melhor } \\
\text { maneira e seqüência de estudar. }\end{array}$ & $\begin{array}{l}\text { Materiais seqüenciados com rigidez. } \\
\text { Obrigatoriedade de cumprir todas as etapas do curso, } \\
\text { mesmo aquelas que tratam de assuntos econteúdos } \\
\text { dominados pelo estudante. }\end{array}$ \\
\hline
\end{tabular}


de curta e longa duração, em diferentes tipos de instituições;

- construção de medidas de avaliação para mensuração do efeito da aplicação da EAD na aprendizagem e na transferência de aprendizagem para o trabalho;

- identificação prévia de variáveis relativas ao contexto de estudo do públicoalvo e que interferem em sua aprendizagem, motivação para aprender, permanência no curso e aplicação no trabalho de novas aprendizagens adquiridas em eventos de EAD;

- aprimoramento das estratégias e ferramentas de aprendizagem colaborativa em ambientes virtuais de aprendizagem;

- ampliação das práticas de inclusão dos interessados, inclusive alunos, no planejamento de cursos a distância, desde a avaliação da necessidade educacional com definição das competências a desenvolver e a descrição do perfil público-alvo, até o desenho e a avaliação da ação educacional;

- avaliação da efetividade de cursos a distância, comparando-os com cursos tradicionais com presença;

- avaliação da efetividade de programas de EAD em seus impactos na organização fornecedora, nas organizações parceiras, clientes e na sociedade, utilizando metodologias já existentes de avaliação educacional, corporativa e de programas sociais.

Porém, há condições necessárias a um futuro melhor. Entre elas, estão a:

-cooperação e intercâmbio entre instituições de ensino superior e pesquisa, universidades, escolas de governo e outras entidades responsáveis por programas de qualificação e formação profissional para produção conjunta de pesquisas que

\section{Quadro 5: Potencialidades da EAD mediada por NTICs}

EAD mediada por NTICs

1. Possibilidade de oferta de feedbacks individuais e contingentes ao desempenho acadêmico do aluno.

2. Uso de hipertexto, multimídia e hiperbases de dados (multimodalidade e experimentação).

3. Acesso facilitado (on-line) a bibliotecas, informações, arquivos eletrônicos.

4. Viabilização e estimulação a participação das pessoas no processo de ensino-aprendizagem.

5. Auxílio aos educadores paraa mapear e monitorar os hábitos de estudo dos alunos.

6. Aumento da interatividade com os materiais didáticos.

7. Facilitação do acompanhamento dos processos de aprendizagem do aluno, bem como dos resultados dessas aprendizagens.

8. Agilização e aumento a efetividade de trabalhos que envolvem busca, localização, coleta e armazenagem de informações.

9. Facilitação a simulação de situações atividades de solução de problemas para repetição e generalização de conhecimentos.

10. Viabilização do trabalho em equipe de pessoas fisicamente distantes entre si.

11. Facilitação para armazenar, recuperar e tratamento de informações coletadas por meio da rede.

12. Destruição de barreiras físicas entre pessoas, possibilitando contatos assíncronos com registro simultâneo da contribuição e mensagens.

13. Ampliação da interação entre os aprendizes.

14. Aumento da aprendizagem, a retenção e generalização de conhecimentos. 
gerem conhecimentos e tecnologias capazes de aumentar a efetividade da EAD.Página: 27

- formação de profissionais para atuação e pesquisa em assuntos concernentes a EAD;

- formação de uma rede de aprendizagem para ampliação e otimização de esforços, visando a melhoria da qualidade da EAD;
- programas de inclusão digital e de familiarização da sociedade com as novas tecnologias da informação e comunicação;

- programas que estimulem a universalização do acesso à aprendizagem contínua e ao longo de toda a vida;

- programas que apóiem pesquisas e formação de profissionais na área de EAD.

(Artigo recebido em 18de julho de 2007. Versão final em 14 de outubro de 2007)

\section{Notas}

${ }^{1}$ São elas: Sabesp, Sadia, Carrefour, Lojas Renner, Rede Bahia, Alcatel, Siemens, Elektro, Banco do Brasil, BankBoston, BNDES, Caixa, Real-ABN, Amro, Visa do Brasil, Natura, CVRD, Amil, Correios, Microsiga, Embratel, Volkswagen.

${ }^{2}$ Universidade Corporativa ABRAMGE, da Associação Brasileira de Medicina em Grupo; Universidade de Alimentos (UAL), da Kraft Foods Brasil e Universidade Corporativa SECOVI (UCS), do Sindicato das Empresas de Compra, Venda, Locação e Administração de Imóveis residenciais e Comerciais de São Paulo.

\section{Referências Bibliográficas}

Anuário Brasileiro Estatístico de Educação Aberta e a Distância. 3ª Edição. São Paulo: Instituto Monitor. 2007.

AbBad, G., Carvalho, R. S., Zerbini, T. Evasão em curso via internet. explorando variáveis explicativas. Revista de administração de empresas - RAE - eletrônica, 5(2), art. 17, jul./dez., 2006.

DeLors, J. A Educação para o Século XXI: questões e perspectivas. Porto Alegre, RS:Artmed, 2005.

EвоLI, M. Educação corporativa no Brasil: mitos e verdades. São Paulo: Editora Gente, 2004.

FILHO, Hélio Chaves (presidente da mesa). Educação a Distância em Organizações Públicas: Mesa Redonda de Pesquisa-Ação. ENAP: 2006.

Peters, O. Didática do ensino a distância: experiências e estágio da discussão numa visão internacional. São Leopoldo, RS: Editora Unisinos, 2001. 
SHIN, N.; KIM, J. An exploratory of learner progress and dropout in Korea National Open University. Distance Education, 20(3), pp. 81-95, 1999.

Xenos, M., Pierrakeas, C.; Pintelas, P. A survey on student dropout rates and dropout causes concerning the students in the Course of Informatics of the Hellenic Open University. Computers \& Education, 39, 361-377, 2002.

VARgas, M. R. M. Barreiras à implantação de programas de educação e treinamento a distância. Tese de Doutorado, Instituto de Psicologia, Universidade de Brasília, 2004.

Zarifian, P. O objetivo da competência. São Paulo: Editora Atlas, 2001.

Zerbini, T., AbBad, G. Impacto de treinamento no trabalho via internet. Revista de Administração de Empresas Eletrônica, 4 (2), 2005.

Zerbini, T., Brauer, S., Meneses, P. P. M., Abbad, G. Percepções sobre educação a distância: limitações e restrições à implantação da Universidade Corporativa do Banco Central do Brasil [CD-Rom]. Em Associação Nacional dos Programas de PósGraduação em Administração (Org.). Anais do XXX ENANPAD. Salvador: ANPAD, 2006. 


\section{Resumo - Resumen - Abstract}

\section{Educação a distância: $\mathrm{O}$ estado da arte e o futuro necessário Gardênia da Silva Abbad}

Este artigo analisa alguns desafios que cercam a adoção da Educação a Distância por instituições de ensino, unidades de formação e qualificação profissional e de educação corporativa. Além disto, é sugerida uma agenda de pesquisa sobre EAD. O artigo trata do papel da EAD na educação continuada de adultos e na ampliação do acesso à aprendizagem, em função da possibilidade de interações assíncronas, mediadas por tecnologias da informação e comunicação. Uma análise da situação EAD no Brasil mostra um grande crescimento da modalidade. Observa-se que ainda são raras as pesquisas sobre EAD no serviço público. Há informações sugerindo que, em órgãos públicos com práticas institucionalizadas de EAD, a modalidade representa uma valiosa e eficaz estratégia de inclusão de pessoas em atividades de ensino-aprendizagem. São analisados alguns importantes desafios ligados à implementação e ao desenho de cursos a distância, e, além disto, é apresentada uma agenda de pesquisas para a área.

Palavras-chave: Educação a distância. Educação corporativa. Educação de adultos.

\section{Educación a distancia: el estado del arte y el futuro necesario Gardênia da Silva Abbad}

Este artículo hace el análisis de algunos desafios para la adopción de la Educación a Distancia (EAD) por parte de instituciones de enseñanza, unidades de formación y calificación profesional y de educación corporativa. Además de esto, hace la sugerencia de una agenda de investigación sobre la EAD. El artículo incluso trata del papel de la EAD en la educación continuada de los adultos y en la ampliación del acceso al aprendizaje, en función de la posibilidad de interaciones asincrónicas, mediante tecnologías de la información y comunicación. Un análisis de la situación de la EAD en Brasil muestra un gran desarrollo de esta modalidad de educación. También ha observado que aún son pocas las investigaciones sobre la EAD en el servicio público. Hay informaciones sugiriendo que, en órganos públicos con prácticas intitucionalizadas, dicha modalidad representa una valiosa y eficaz estratégia de inclusión de personas en actividades de enseñanza y aprendizaje. Algunos desafios importantes que tienen a ver con la implementación y el diseño de cursos a distancia son analizados.

Palabras-clave: Educación a distancia. Educación corporativa. Educación de adultos.

\section{Distance learning: the state of the art and the needed future Gardênia da Silva Abbad}

The present article analyses some challenges around the adoption of e-learning in teaching institutions, as well as units of professional induction and qualification courses and of corporate education. Furthermore, it suggests a research agenda on e-learning. The article is concerned with the role e-learning plays in adults' continued education and in the enlargement of access to learning, according to the possibility of asynchronal interactions provided by technologies of information and communication. Then, an analysis of the state-of-the-art of e-learning in Brazil shows a great development of the modality. It can be observed that researches about e-learning in the public service area are still rare. There is some information suggesting that in public agencies with institutionalized practices of e-learning, the modality represents valuable and effective strategies for including people in teaching-learning activities. It, then, analyses some important challenges 